\title{
Determinants of nutrition status in children aged 6-59 months, in Kiandutu informal settlement, Thika, Kenya
}

\author{
R.1 Ireri ${ }^{1}$, A.M. Nyanchoka ${ }^{2}$, M. Mburu ${ }^{2}$, J. Ndungu ${ }^{3}$ and M.S. Kiarie ${ }^{2}$ \\ ${ }^{1}$ Department of Clinical Medicine, Kenya Medical Training College, Thika, \\ ${ }^{2}$ Department of Nutrition and Dietetics, Kenya Medical Training College, Thika and \\ ${ }^{3}$ Department of Nutrition and Dietetics, Kenya Medical Training College, Kapenguria, Kenya
}

Optimal nutrition in children is the cornerstone of good health ${ }^{(1)}$. About a third of the world's population lives in informal settlements, and the population is rapidly growing every year ${ }^{(2,3)}$. Poor livelihoods in informal settlements have been linked with poor nutrition and ill-health in children ${ }^{(3,4)}$. Childhood malnutrition is an underlying cause of the increased risk of infections, reduced quality of life, impaired physical, and cognitive development ${ }^{(4)}$. Even though poor nutrition affects the general population, children living in informal settlements have been reported to be more vulnerable to undernutrition, attributed to lack of basic needs and limited social infrastructure ${ }^{(5)}$. This study aimed to assess the determinants of nutritional status of children aged 6-59 months in Kiandutu informal settlement; Thika, Kenya.

A community-based cross-sectional design was used in this study. Multi staged stratified sampling followed by systematic random sampling was used to recruit 170 caregivers with children aged 6-59 months from different households living in Kiandutu Informal Settlement, Thika, Kiambu County, Kenya. A structured questionnaire was used to collect data. Anthropometric measurements were performed using standardized tools and methods. Data were analyzed using WHO-Anthro Analyzer and IBM SPSS version 26.0.

The results of this study revealed that $18.8 \%$ and $34.7 \%$ children were underweight and stunted. The prevalence of wasting using WHZ was $15.3 \%$ and $9 \%$ using MUAC. Children who were exclusively breastfed for less than 6 months were statistically associated with being underweight and stunted. Stunting and wasting was significantly associated with the house household decision-maker $(\mathrm{p}<0.05)$, with children living in households whose decision-maker was the father, had a higher likelihood to develop wasting and stunting than those living in households whose decision-makers was the mother, both parents, and other family members. The type of food feed first to the child when complementary feeding was initiated was correlated with stunting $(\mathrm{p}<0.05)$. Weight-for-height and height-for-age Z-scores were significantly associated with child wellness clinic visits for monthly check-ups $(\mathrm{p}<0.05)$. and child well clinic visits $(\mathrm{p}<0.05$. Wasting $(\mathrm{MUAC})$ was significantly associated with child age group $(\mathrm{p}<0.001)$, child breast feeding $(p<0.05)$, reports of diarrhea during the last two weeks' prior the survey $(p<0.01)$ and child wellness clinic visit $(\mathrm{p}=0.05)$.

It is evident that childhood malnutrition remains an important public health nutrition concern in informal settlements. There is a need to address access to sustainable diets, nutrition education, and improving livelihoods of populations in informal settlements.

\section{References}

1. WHO. NHD, SDE: Rome, Italy 2000.

2. Lee GO, Olortegui MP et al. (2016) BMC Int Health Hum Rights 1;16(1):26.

3. Olack B, Burke H et al. (2011) J Health Popul Nutr 29(4):357.

4. Dessie ZB, Fentie M et al. (2019) BMC pediat 19(1):83.

5. Amare ZY, Ahmed ME et al. (2019) Glob health 15(1):62. 